\title{
A multi-institutional cohort study confirming the risks of Clostridium difficile infection associated with prolonged antibiotic prophylaxis
}

Katherine A. Kirkwood, MS, ${ }^{a}$ Brian C. Gulack, MD, MHS, ${ }^{b}$ Alexander Iribarne, MD, MS, Michael E. Bowdish, MD, ${ }^{\mathrm{d}}$ Giampaolo Greco, PhD, ${ }^{\mathrm{e}}$ Mary Lou Mayer, BSN,${ }^{\mathrm{f}}$ Karen O'Sullivan, MPH, Annetine C. Gelijns, PhD, ${ }^{\mathrm{e}}$ Nishit Fumakia, MD, ${ }^{\mathrm{g}}$ Ravi K. Ghanta, MD, ${ }^{\mathrm{h}}$ Jesse M. Raiten, MD, ${ }^{\mathrm{i}}$ Anuradha Lala, MD, ${ }^{j}$ Joseph S. Ladowski, MD, ${ }^{\mathrm{k}}$ Eugene H. Blackstone, MD, ${ }^{1}$ Michael K. Parides, PhD, ${ }^{a}$ Alan J. Moskowitz, MD, ${ }^{\mathrm{e}}$ and Keith A. Horvath, $\mathrm{MD}^{\mathrm{m}}$

\section{ABSTRACT}

Objectives: The incidence and severity of Clostridium difficile infection (CDI) have increased rapidly over the past 2 decades, particularly in elderly patients with multiple comorbidities. This study sought to characterize the incidence and risks of these infections in cardiac surgery patients.

Methods: A total of 5158 patients at 10 Cardiothoracic Surgical Trials Network sites in the US and Canada participated in a prospective study of major infections after cardiac surgery. Patients were followed for infection, readmission, reoperation, or death up to 65 days after surgery. We compared clinical and demographic characteristics, surgical data, management practices, and outcomes for patients with CDI and without CDI.

Results: $C$ difficile was the third most common infection observed $(0.97 \%)$ and was more common in patients with preoperative comorbidities and complex operations. Antibiotic prophylaxis for $>2$ days, intensive care unit stay $>2$ days, and postoperative hyperglycemia were associated with increased risk of CDI. The median time to onset was 17 days; $48 \%$ of infections occurred after discharge. The additional length of stay due to infection was 12 days. The readmission and mortality rates were 3 -fold and 5-fold higher, respectively, in patients with CDI compared with uninfected patients.

Conclusions: In this large multicenter prospective study of major infections following cardiac surgery, CDI was encountered in nearly $1 \%$ of patients, was frequently diagnosed postdischarge, and was associated with extended length of stay and substantially increased mortality. Patients with comorbidities, longer surgery time, extended antibiotic exposure, and/or hyperglycemic episodes were at increased risk for CDI. (J Thorac Cardiovasc Surg 2018;155:670-8)

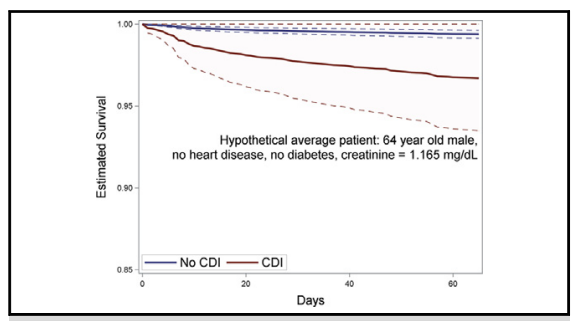

Survival by time-varying Clostridium difficile infection status.

\section{Central Message}

Prolonged antibiotic prophylaxis ( $>48$ hours) was associated with risk of Clostridium difficile infection (CDI), the third most common major infection after cardiac surgery. CDI was associated with a substantial increase in mortality.

\section{Perspective}

The incidence and severity of Clostridium difficile infection (CDI) has increased recently. Our study found that CDI was associated with longer length of stay, frequent readmissions, and decreased survival. Median time to onset of CDI was $>2$ weeks postoperatively, with nearly one-half of patients $(48 \%)$ first diagnosed after discharge. Limiting antibiotic prophylaxis to 2 days and controlling blood glucose levels may reduce the incidence of CDI.

See Editorial Commentary page 679.

See Editorial page 659. \begin{tabular}{l}
\hline From the ${ }^{\mathrm{a}}$ International Center for Health Outcomes and Innovation Research \\
(InCHOIR) and Center for Biostatistics in the Department of Population Health \\
Science and Policy, and ${ }^{\mathrm{e}}$ International Center for Health Outcomes and Innovation \\
Research, Department of Population Health Science and Policy, Icahn School of \\
Medicine at Mount Sinai; ${ }^{\mathrm{j}}$ Zena and Michael A. Wiener Cardiovascular Institute, \\
Icahn School of Medicine, New York, NY; ${ }^{\mathrm{b}}$ Division of Cardiovascular and \\
Thoracic Surgery, Department of Surgery, Duke Health, Durham, NC; ${ }^{\mathrm{c}}$ Cardiac \\
Surgery, Dartmouth-Hitchcock Medical Center, Lebanon, NH; ${ }^{\mathrm{d}}$ Department of \\
Surgery, Keck School of Medicine of USC, University of Southern California, \\
Los Angeles, Calif; ${ }^{\mathrm{f}}$ Division of Cardiovascular Surgery, Department of Surgery, \\
University of Pennsylvania School of Medicine; ${ }^{\mathrm{i}}$ Department of Anesthesiology \\
and Critical Care, University of Pennsylvania School of Medicine, Philadelphia, \\
Pa; ${ }^{\mathrm{g}}$ Division of Cardiovascular Surgery, Toronto General Hospital, Toronto, On- \\
tario, Canada; ${ }^{\mathrm{h}}$ Michael E. DeBakey Department of Surgery, Baylor College of \\
Medicine, Houston, Tex; ${ }^{\mathrm{k}}$ Indiana Ohio Heart, Fort Wayne, Ind; ${ }^{\mathrm{l} C a r d i o t h o r a c i c}$
\end{tabular}
Research, Cleveland Clinic, Cleveland, Ohio; and ${ }^{\mathrm{m}}$ Clinical Transformation, Association of American Medical Colleges, Washington, DC.

Registered at ClinicalTrials.gov (NCT01089712).

Funding for this work was provided through a cooperative agreement (U01 HL088942) between the National Heart, Lung, and Blood Institute; the National Institute of Neurological Disorders and Stroke; and the Canadian Institutes of Health Research.

Received for publication May 15, 2017; revisions received Aug 25, 2017; accepted for publication Sept 18, 2017; available ahead of print Oct 25, 2017.

Address for reprints: Annetine C. Gelijns, PhD, Department of Population Health Science and Policy, Icahn School of Medicine at Mount Sinai, One Gustave L. Levy Place, Box 1077, New York, NY 10029 (E-mail: annetine.gelijns@mssm.edu). $0022-5223 / \$ 36.00$

Copyright (C) 2017 by The American Association for Thoracic Surgery https://doi.org/10.1016/j.jtcvs.2017.09.089 

Abbreviations and Acronyms
$\mathrm{CDC}=$ Centers for Disease Control and Prevention
$\mathrm{CDI}=$ Clostridium difficile infection
$\mathrm{CHF}=$ congestive heart failure
$\mathrm{CI}=$ confidence interval
COPD $=$ chronic obstructive pulmonary disease
CTSN $=$ Cardiothoracic Surgery Trials Network
$\mathrm{HR}=$ hazard ratio
ICU = intensive care unit
IQR = interquartile range
LOS = length of stay
SSI = surgical site infection
VAD $=$ ventricular assist device

\begin{abstract}
Scanning this $\mathrm{QR}$ code will take you to the appendix for this article.
\end{abstract}

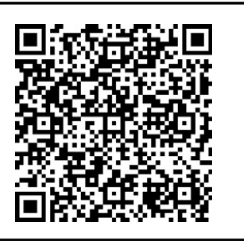

Clostridium difficile, a gram-positive, spore-forming anaerobic bacterium, is the most common source of hospital-acquired gastrointestinal infection. ${ }^{1-7} \mathrm{C}$ difficile infection (CDI) can cause a wide spectrum of illness, ranging from mild diarrhea to pseudo-obstruction, pseudomembranous colitis, prolonged ileus, toxic megacolon, large bowel perforation, hemodynamic collapse, multisystem organ failure, shock, and death. . $^{3,6,8-10}$

Both the incidence and severity of CDI have been increasing worldwide since the mid- to late-1990s, as evidenced by a variety of single-site, multicenter, and population-based studies. ${ }^{1-5,8,10-27}$ Although some of the increase in observed incidence may be due to the adoption of newer, more sensitive nucleic acid amplification tests, the rates of colectomy and mortality continue to climb. ${ }^{5-7,10-14,16,18,20,23}$ Estimates of hospital cost increases directly due to CDI are as high as $\$ 77,000,{ }^{1,4,19,20,28}$ with cumulative annual costs estimated to exceed \$200 million for cardiac surgery patients alone ${ }^{24}$ and nearly $\$ 5$ billion for CDIs in acute care facilities in the United States. ${ }^{25,29,30}$ The US Centers for Disease Control and Prevention (CDC) has identified CDI as an important cause of infectious disease-related death and has made its prevention a national priority. ${ }^{25}$

Advanced age, blood product transfusions, heart failure, peripheral vascular disease, chronic obstructive pulmonary disease (COPD), liver disease, diabetes, history of stroke, renal failure, mechanical ventilation, urinary catheter use, decubitus ulcers, health care exposure (eg, hospitalization), and antibiotic exposure have been identified as risk factors for CDI. ${ }^{8,9,24,31-34}$ Consequently, cardiac surgery would appear to be a particularly vulnerable population; yet the literature has focused primarily on surgical site infections (SSIs) and bloodstream infections in this population. ${ }^{35,36}$

The Cardiothoracic Surgical Trials Network (CTSN), funded by the National Institutes of Health and the Canadian Institutes of Health Research, recently conducted a large multicenter prospective cohort study with the primary objective of identifying management practices associated with infections occurring within 65 days after cardiac surgery. ${ }^{37}$ The CTSN study identified CDI as the third most common major infection, following pneumonia and bloodstream infection. To provide a more thorough understanding of CDI and how it affects patients undergoing cardiac surgery, we analyzed this cohort to determine the incidence of CDI and explore its association with adverse outcomes, as well as demographic variables and management practices associated with increased risk of developing CDI.

\section{METHODS \\ Population}

The study cohort included all 5158 patients at 10 CTSN sites in the United States and Canada who participated in the prospective Management Practices and the Risk of Infection Following Cardiac Surgery study (ClinicalTrials.gov; NCT01089712) (Figure 1). ${ }^{37}$ All patients at the participating sites who had a clinical indication for cardiac surgery, did not have an active systemic infection, were at least 18 years of age, and provided written informed consent were enrolled between February and September 2010. The study received Institutional Review Board approval at each participating clinical center and at the data coordinating center.

\section{Data}

Demographic data, baseline laboratory values, comorbidities, surgical data, and management practices (eg, antimicrobial prophylaxis, glycemic control) were collected for the prospective cohort study. Comorbidities recorded included hypertension, hypercholesterolemia, diabetes, chronic lung disease, renal insufficiency (ie, history of renal insufficiency/failure and/or serum creatinine $>2.0$ preoperatively), congestive heart failure (CHF), history of infective endocarditis, cerebrovascular accident, peripheral vascular disease, congenital heart disease, and valvular heart disease. Surgical characteristics captured included procedure status (ie, elective, urgent, or emergent), procedure, type of incision, operative time, use and duration of cardiopulmonary bypass and circulatory arrest, and blood transfusions.

Participants were followed for up to 65 days to determine the incidences of major and minor infections, all-cause mortality, reoperation, and hospital readmission. The 10 major infections included were deep incisional SSI occurring at the primary chest incision, deep incisional SSI occurring at a secondary incision site (eg, saphenous harvest and groin cannulation sites), mediastinitis, infectious myocarditis or pericarditis, endocarditis, cardiac device infection, pneumonia, empyema, $C$ difficile colitis, and bloodstream infection. CDI was diagnosed according to standard clinical practice at each site. Minor infections were defined as primary and secondary superficial incisional SSIs, symptomatic urinary tract infections, and asymptomatic bacteriuria. Infections were classified based on definitions from the CDC and the National Healthcare Safety Network surveillance, ${ }^{38}$ and all major infections were adjudicated by an Event Adjudication Committee that included 3 infectious disease experts. Infections other than $C$ difficile in this cohort have been previously described in detail. ${ }^{37,39,40}$ 


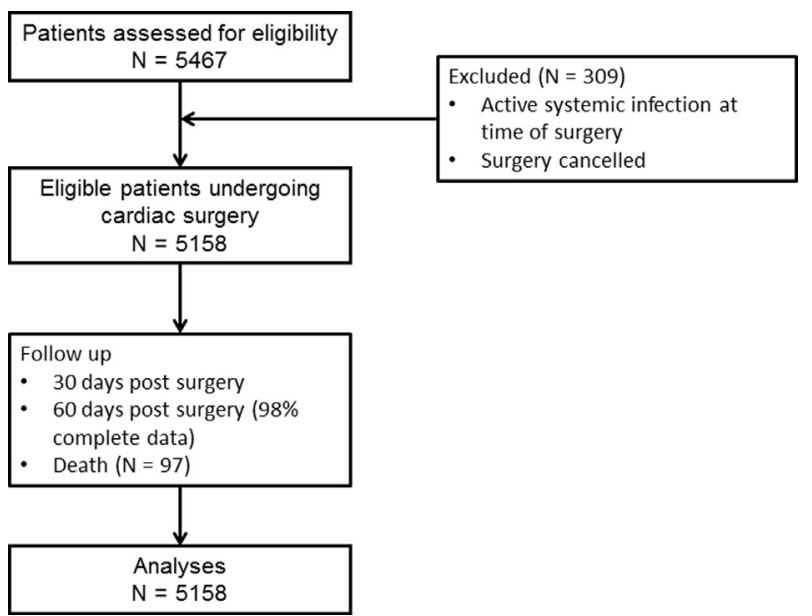

FIGURE 1. CONSORT diagram.

All data were entered into an electronic data capture system and submitted to the data coordinating center, which was responsible for electronic and local monitoring of the data for quality assurance.

\section{Statistical Analysis}

Univariable proportional hazards regression models were used to assess differences in patient demographic data, operative characteristics, and postoperative management by a CDI or no CDI during follow-up. We adjusted for patient-level risk factors and management factors but not for site, to avoid obscuring risks related to management practices that may vary by site. Patients missing the 60-day follow-up visit were censored at the time of last contact.

Variables with a $P$ value $\leq .20$ were considered when building the multivariable proportional hazards model of time to onset of CDI using a backward stepwise process. This model included death as a competing risk using the method of Fine and Gray. ${ }^{41}$ Assumptions of the Fine-Gray model were checked by testing for an interaction between time and each of the covariates and by plotting the Schoenfeld-type residuals over time. $^{42}$

An interaction between diabetes and hyperglycemia was explored, given that some previous studies have found a differential risk of hyperglycemia. ${ }^{43-46}$ Residuals were plotted to confirm that continuous numerical variables included in the final model could be treated as linear. Akaike information criterion values were considered in final model selection.

The cumulative incidence function of CDI was plotted, again treating death as a competing risk. ${ }^{41}$ A multivariable extended Cox model was also used to assess the relationship between time to death and a time-varying indicator for CDI, adjusting for factors found to be predictive of mortality in the cohort as a whole ${ }^{37}$ and for other non- $C$ difficile infection as a time-varying covariate. Survival estimates for the hypothetical average patient in the cohort (age, 64 years; serum creatinine, $1.165 \mathrm{mg} / \mathrm{dL}$; no diabetes or heart failure; no other infection) were generated from the proportional hazards regression model and plotted by time-varying CDI status.

A multistate time-inhomogeneous Markov model $^{47}$ was used to determine the excess length of stay (LOS) of the index hospitalization due to CDI. The model assumed a single initial state (index surgical procedure), one intermediate state (CDI), and 2 absorbing states (hospital discharge and death). A bootstrap standard error and $95 \%$ confidence interval (CI) for the excess LOS was computed based on 1000 bootstrap samples.
All variables included in the final models had a $P$ value $\leq .05$. All analyses were conducted using SAS version 9.4 (SAS Institute, Cary, NC) and R 3.1.1 (R Institute for Statistical Computing, Vienna, Austria).

\section{RESULTS \\ Patient Characteristics}

The study cohort included a total of 5158 patients who enrolled in the study and underwent cardiac surgery between February and September 2010. Patient characteristics of the overall cohort have been reported previously ${ }^{37}$ and are summarized in Table 1. In brief, the mean age was $64.4 \pm 13.2$ years, median body mass index was $28.2 \mathrm{~kg} / \mathrm{m}^{2}$ (interquartile range [IQR] 25.1-32.3), and the proportion of women was $33.1 \%$. Common comorbidities included diabetes mellitus ( $22.7 \%$ of patients), heart failure $(29.2 \%)$, and COPD $(14.5 \%)$. The most common procedures were isolated valve surgery $(36.4 \%)$ and isolated coronary artery bypass grafting (32.5\%); $90.5 \%$ of patients underwent sternotomy, and $18.6 \%$ of patients had undergone previous cardiac surgery.

CDI was the third most common infection observed $(0.97 \%)$ after pneumonia $(2.38 \%)$ and bloodstream infections $(1.09 \%)$. Compared with patients without CDI, those with CDI were more likely to have a higher serum creatinine level, a lower ejection fraction, previous cardiac surgery, and renal failure (with or without dialysis). Median surgery and bypass times were longer in the patients with CDI, and patients with CDI were more likely to have undergone combined procedures, ventricular assist device (VAD) placement or replacement, or heart transplantation than patients without CDI. Patients with CDI were also more likely to have received more than 48 hours of postoperative antibiotic prophylaxis, were less likely to have received second-generation cephalosporins as postoperative antibiotic prophylaxis, and were more likely to have longer times in the intensive care unit (ICU) and on ventilation (Table 2). Postoperative hyperglycemic episodes and infections other than CDI were also more common in the patients with CDI.

\section{Frequency, Severity, and Timing of CDI}

A total of 52 CDIs were identified in 50 patients during the 65 -day follow-up period $(0.97 \%)$. Two of the patients with CDI (4\%) required total colectomy. Median time to CDI onset was 17 days after surgery (IQR, 6-28 days; Figure 2). Onset of CDI occurred before hospital discharge in $52 \%$ of patients $(n=26)$ (Table 3$)$, and on the day of discharge in 2 patients. Ten patients had a major infection before the onset of CDI $(20.0 \%), 6$ patients had a minor infection before CDI (12.0\%), and 2 patients had both a major and a minor infection before CDI.

\section{Risk Factors Associated With CDI}

Renal failure was the sole preoperative patient characteristic associated with a higher risk of CDI in multivariable 
TABLE 1. Patient and operative characteristics

\begin{tabular}{|c|c|c|c|c|c|}
\hline Characteristic & $\begin{array}{c}\text { C difficile } \\
(\mathbf{n}=\mathbf{5 0})\end{array}$ & $\begin{array}{c}\text { No } C \text { difficile } \\
(\mathbf{n}=\mathbf{5 1 0 8})\end{array}$ & $\begin{array}{c}\text { Overall } \\
(\mathbf{n}=\mathbf{5 1 5 8})\end{array}$ & Hazard ratio & $P$ value $*$ \\
\hline \multicolumn{6}{|l|}{ Demographics } \\
\hline Age, y, mean (SD) & $64.5(13.4)$ & $64.4(13.2)$ & $64.4(13.2)$ & 1.001 & .9533 \\
\hline Male sex, n (\%) & $36(72.0)$ & $3414(66.8)$ & $3450(66.9)$ & 1.264 & .4577 \\
\hline Race, n (\%) & & & & & .0581 \\
\hline White & $37(74.0)$ & $4285(83.9)$ & $4322(83.8)$ & 0.420 & \\
\hline Black & $11(22.0)$ & $529(10.4)$ & $540(10.5)$ & & \\
\hline Other & $2(4.0)$ & $294(5.8)$ & $296(5.7)$ & 0.332 & \\
\hline BMI, median (IQR) & $28.8(25.0-34.2)$ & $28.2(25.1-32.2)$ & $28.2(25.1-32.3)$ & 1.003 & .8847 \\
\hline \multicolumn{6}{|l|}{ Baseline laboratory values, median (IQR) } \\
\hline $\mathrm{WBC}, \times 10^{3} / \mathrm{mL}$ & $7.0(5.6-8.6)$ & $7.0(5.7-8.4)$ & $7.0(5.7-8.4)$ & 0.991 & .8799 \\
\hline Creatinine, $\mathrm{mg} / \mathrm{dL}$ & $1.2(1.0-1.6)$ & $1.0(0.8-1.2)$ & $1.0(0.8-1.2)$ & 1.186 & .0027 \\
\hline Hemoglobin, g/dL & $13.1(11.0-14.4)$ & $13.4(12.0-14.5)$ & $13.4(12.0-14.5)$ & 0.890 & .1161 \\
\hline \multicolumn{6}{|l|}{ Cardiac morbidity } \\
\hline Heart failure, n (\%) & $23(46.0)$ & $1482(29.0)$ & $1505(29.2)$ & 2.093 & .0092 \\
\hline Ejection fraction, $\%$, median (IQR) & $50.0(35.0-55.0)$ & $55.0(48.0-60.0)$ & $55.0(48.0-60.0)$ & 0.962 & $<.0001$ \\
\hline Previous cardiac surgery, n (\%) & $16(32.0)$ & $942(18.4)$ & $958(18.6)$ & 2.071 & .0163 \\
\hline Baseline circulatory support, n (\%) & $3(6.0)$ & $132(2.6)$ & $135(2.6)$ & 2.383 & .1447 \\
\hline History of infective endocarditis, $\mathrm{n}(\%)$ & $0(0.0)$ & $61(1.2)$ & $61(1.2)$ & & .9817 \\
\hline \multicolumn{6}{|l|}{ Noncardiac morbidity } \\
\hline Diabetes, $\mathrm{n}(\%) \dagger$ & $12(24.0)$ & $1157(22.7)$ & $1169(22.7)$ & 1.084 & .8081 \\
\hline COPD, n (\%) & & & & & .1895 \\
\hline None & $38(76.0)$ & $4374(85.6)$ & $4412(85.5)$ & & \\
\hline Mild or moderate & $10(20.0)$ & $634(12.4)$ & $644(12.5)$ & 1.814 & \\
\hline Severe & $2(4.0)$ & $100(2.0)$ & $102(2.0)$ & 2.303 & \\
\hline Renal failure, $\mathrm{n}(\%)$ & & & & & .0008 \\
\hline No & $36(72.0)$ & $4526(88.6)$ & $4562(88.4)$ & & \\
\hline Yes, dialysis-dependent & $5(10.0)$ & $85(1.7)$ & $90(1.7)$ & 2.309 & \\
\hline Yes, not dialysis-dependent & $9(18.0)$ & $497(9.7)$ & $506(9.8)$ & 7.428 & \\
\hline History of cerebrovascular accident & $7(14.0)$ & $513(10.0)$ & $520(10.1)$ & 1.458 & .3551 \\
\hline \multicolumn{6}{|l|}{ Operative } \\
\hline Surgery time, h, median (IQR) & $5.1(4.2-6.6)$ & $4.2(3.3-5.2)$ & $4.2(3.3-5.2)$ & 1.458 & $<.0001$ \\
\hline Bypass time, $\mathrm{h}$, median (IQR) $\ddagger$ & $2.1(1.6-3.1)$ & $1.8(1.3-2.3)$ & $1.8(1.3-2.3)$ & 1.523 & .0011 \\
\hline Sternotomy, n (\%) & $48(96.0)$ & $4621(90.5)$ & $4669(90.5)$ & 2.512 & .2018 \\
\hline Surgery type, n (\%) & & & & & .4590 \\
\hline Elective & $33(66.0)$ & $3773(73.9)$ & $3806(73.8)$ & & \\
\hline Urgent & $15(30.0)$ & $1199(23.5)$ & $1214(23.5)$ & 1.430 & \\
\hline Emergent & $2(4.0)$ & $136(2.7)$ & $138(2.7)$ & 1.681 & \\
\hline Procedure, $\mathrm{n}(\%)$ & & & & & $<.0001$ \\
\hline Isolated CABG & $9(18.0)$ & $1668(32.7)$ & $1677(32.5)$ & 0.407 & \\
\hline Isolated valve & $12(24.0)$ & $1866(36.5)$ & $1878(36.4)$ & 0.487 & \\
\hline $\mathrm{CABG}+$ valve & $9(18.0)$ & $683(13.4)$ & $692(13.4)$ & & \\
\hline Transplant or VAD & $10(20.0)$ & $112(2.2)$ & $122(2.4)$ & 6.499 & \\
\hline Thoracic aortic & $6(12.0)$ & $422(8.3)$ & $428(8.3)$ & 1.080 & \\
\hline Other & $4(8.0)$ & $357(7.0)$ & $361(7.0)$ & 0.847 & \\
\hline \multicolumn{6}{|l|}{ Other } \\
\hline Transferred from outside hospital, n (\%) & $4(8.0)$ & $717(14.0)$ & $721(14.0)$ & 0.535 & .2302 \\
\hline Preoperative antibiotic prophylaxis, n (\%) & & & & & .0344 \\
\hline First-generation cephalosporin & $23(46.0)$ & $1836(36.0)$ & $1859(36.1)$ & 0.922 & \\
\hline Second-generation cephalosporin & $13(26.0)$ & $2232(43.7)$ & 2245 (43.6) & 0.431 & \\
\hline Other & $14(28.0)$ & $1036(20.3)$ & $1050(20.4)$ & & \\
\hline Days admitted before surgery, median (IQR) & $0.0(0.0-4.0)$ & $0.0(0.0-2.0)$ & $0.0(0.0-2.0)$ & 1.008 & 7761 \\
\hline
\end{tabular}

$S D$, Standard deviation; $B M I$, body mass index; $I Q R$, interquartile range; $W B C$, white blood cell; $C O P D$, chronic obstructive pulmonary disease; $C A B G$, coronary artery bypass grafting; $V A D$, ventricular assist device. *Based on a Cox proportional hazards model in which the outcome is time to $C$ difficile infection and the predictor is patient or operative characteristic. $\dagger$ Insulin or oral medications. $\ddagger 91.1 \%$ of patients had on-pump surgical procedures. 
TABLE 2. Postoperative characteristics

\begin{tabular}{|c|c|c|c|c|c|}
\hline Characteristic & $\begin{array}{c}C \text { difficile } \\
(\mathbf{n}=\mathbf{5 0})\end{array}$ & $\begin{array}{c}\text { No } C \text { difficile } \\
(\mathrm{n}=\mathbf{5 1 0 8})\end{array}$ & $\begin{array}{c}\text { Overall } \\
(\mathrm{n}=\mathbf{5 1 5 8})\end{array}$ & Hazard ratio & $P$ value* \\
\hline Days of postoperative antibiotic prophylaxis, n (\%) & & & & & $<.0001$ \\
\hline $2(24-48 \mathrm{~h})$ & $13(26.0)$ & 2107 (41.2) & $2120(41.1)$ & & \\
\hline $1(0-24 \mathrm{~h})$ & $11(22.0)$ & $2585(50.6)$ & $2596(50.3)$ & 0.692 & \\
\hline $3(>48 \mathrm{~h})$ & $26(52.0)$ & $416(8.1)$ & $442(8.6)$ & 10.033 & \\
\hline Postoperative antibiotic prophylaxis, $\mathrm{n}(\%)$ & & & & & .0358 \\
\hline First-generation cephalosporin & $19(38.0)$ & $1721(33.7)$ & $1740(33.7)$ & 0.721 & \\
\hline Second-generation cephalosporin & $14(28.0)$ & $2270(44.4)$ & $2284(44.3)$ & 0.404 & \\
\hline Other & $17(34.0)$ & $1117(21.9)$ & $1134(22.0)$ & & \\
\hline ICU LOS, d, median (IQR) & $5.0(2.0-8.0)$ & $2.0(1.0-3.0)$ & $2.0(1.0-3.0)$ & 1.069 & $<.0001$ \\
\hline Ventilation duration, d, median (IQR) & $1.0(0.6-2.1)$ & $0.6(0.4-1.0)$ & $0.6(0.4-1.0)$ & 1.087 & .0001 \\
\hline Packed RBCs, units, median (IQR) $\dagger$ & $2.0(0.0-8.0)$ & $0.0(0.0-3.0)$ & $0.0(0.0-3.0)$ & 1.225 & $<.0001$ \\
\hline $\begin{array}{l}\text { LOS from surgery (truncated at onset of } C \text { difficile), } \\
\text { d, median (IQR) }\end{array}$ & $10.0(7.0-17.0)$ & $7.0(6.0-10.0)$ & $7.0(6.0-10.0)$ & 1.069 & $<.0001$ \\
\hline Non- $C$ difficile infection, $\mathrm{n}(\%) \ddagger$ & $14(28.0)$ & $551(10.8)$ & $565(11.0)$ & 3.180 & .0002 \\
\hline Hyperglycemia, n (\%) $\|$ & $37(74.0)$ & $2191(43.0)$ & $2228(43.3)$ & 3.766 & $<.0001$ \\
\hline
\end{tabular}

$I C U$, Intensive care unit; $L O S$, length of stay; $I Q R$, interquartile range; $R B C$, red blood cell. *Based on a Cox proportional hazards model in which the outcome is time to $C$ difficile infection and the predictor is postoperative characteristic. $\dagger 48.1 \%$ of patients received packed RBC transfusions. $\ddagger$ Onset of non-C difficile infection before the onset of $C$ difficile infection. ||Hyperglycemia was defined as 1 or more blood sugar measurements above $180 \mathrm{mg} / \mathrm{dL}$ during the first $48 \mathrm{~h}$ postoperatively.

analysis $(P=.004)$; hazard ratio for dialysis-dependent renal failure compared with no renal failure was 5.08 (95\% CI, 1.94-13.28). Approximately one-half of patients were admitted on the day of surgery (median days admitted before surgery, 0.0; IQR, 0.0-2.0); preoperative LOS was not associated with an increased risk of CDI in the multivariable model. Operative and postoperative variables associated with greater CDI risk include hyperglycemia $(\mathrm{HR}=2.894, P=.0011 ; 95 \% \mathrm{CI}$, $1.53-5.47 ; P=.001)$ and days of postoperative antibiotic prophylaxis (HR $=5.356, P<.0001$ for 3 days vs 2 days; 95\% CI, 2.61-10.99; $P<.001)$. An ICU LOS $>2$ days was also associated with increased risk of CDI (HR, $2.451, P=.0079 ; 95 \%$ CI, 1.27-4.75; $P=.008)$ (Figure 3). There was no evidence of a differential effect of hyperglycemia by diabetes status $(P=.327)$.

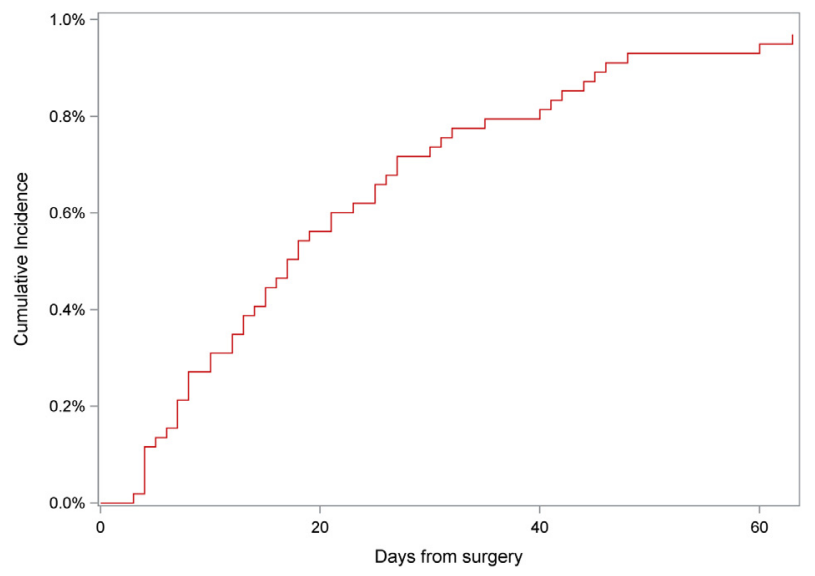

FIGURE 2. Cumulative incidence of $C$ difficile infections.

\section{LOS and Readmissions}

For the 26 patients whose onset of CDI occurred during the index hospitalization, the observed mean LOS from hospital admission was $35.3 \pm 21.6$ days, compared with $17.4 \pm 12.0$ days for patients diagnosed with CDI after discharge and $11.0 \pm 9.1$ days for the patients without CDI. A multistate Markov model was used to estimate the incremental LOS of the index hospitalization following surgery; the mean excess LOS of the index hospitalization due to CDI was $12.3 \pm 3.2$ days (bootstrap 95\% CI, 7.39-17.76).

Thirteen patients who acquired CDI during the follow-up period were readmitted a total of 15 times within the first 30 days after surgery $(0.43$ readmissions per patient month of follow-up), whereas 602 patients without CDI were readmitted 642 times within the first 30 days after surgery (0.13 readmissions per patient month of follow-up). Over the entire 65-day follow up period, readmission rates were

TABLE 3. Infection timing for patients with $C$ difficile infection $(\mathbf{n}=\mathbf{5 0})$

\begin{tabular}{lc}
\hline \multicolumn{1}{c}{ Timing } & Value \\
\hline C difficile onset & $26(52.0)$ \\
$\quad$ Before index hospital discharge, $\mathrm{n}(\%)$ & $17.0(8.0-30.0)$ \\
Time of onset, d, median (IQR) & \\
Other infections, n (\%) & $10(20.0)$ \\
Major infection before $C$ difficile & $6(12.0)$ \\
Minor infection before $C$ difficile & $14(28.0)$ \\
Any infection (major or minor) before $C$ difficile & \\
\hline IQR, Interquartile range.
\end{tabular}

$I Q R$, Interquartile range. 


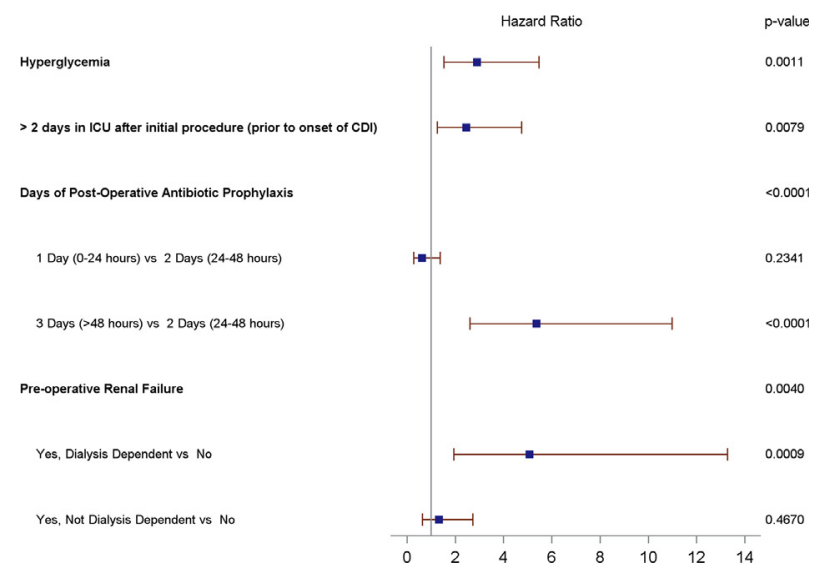

FIGURE 3. Risk factors for $C$ difficile infections. Determined by using a multivariate proportional hazards regression model with death as a competing risk. ICU, Intensive care unit; CDI, Clostridium difficile infection.

0.23 per patient month of follow-up for patients with CDI, compared with 0.09 for those without CDI.

\section{CDI and Mortality}

Mortality during the 65-day follow-up period was higher in the patients with CDI compared with those without CDI $(10.0 \%$ vs $1.8 \% ; P<.001)$. In a proportional hazards regression model treating $\mathrm{CDI}$ as a time-dependent variable, CDI had a substantial impact on survival (HR, 5.449; 95\% CI, 2.14-13.87). The model included non-C difficile infection as a time-varying covariate (HR, 4.063; 95\% CI, 2.49-6.62). The model also adjusted for male sex (HR, 0.535; 95\% CI, 0.36-0.80), age (HR, 1.036; 95\% CI, 1.02-1.05), baseline serum creatinine (HR, 1.20; 95\% CI, 1.09-1.31), CHF (HR, 2.011; 95\% CI, 1.34-3.02), and diabetes (HR, 1.569; 95\% CI, 1.03-2.38), all of which were previously identified as predictors of mortality independent of CDI (Table 4). ${ }^{37}$ The effect of CDI on survival for an average patient in the cohort (male, age 64, serum creatinine $1.165 \mathrm{mg} / \mathrm{dL}$, no diabetes or heart failure) is shown in the Central Picture.

\section{DISCUSSION}

Most previous studies of major infections in cardiac surgery patients have focused on a subset of infections, predominantly SSIs and bloodstream infections, ${ }^{35,36}$ yet a recent large prospective cohort study identified CDI as the third most common major infection after pneumonia and bloodstream infections. ${ }^{37}$ Most previous studies have focused on the first 30 days after surgery and/or the index hospitalization period because this is the time frame in which events are collected for national databases, such as the Premier Perspective Comparative database, the Nationwide Inpatient Sample database, and the Society of Thoracic Surgeons database. ${ }^{24,35,48}$
TABLE 4. Impact of $C$ difficile infection on mortality

\begin{tabular}{|c|c|c|c|}
\hline Variable & $\begin{array}{l}\text { Hazard } \\
\text { ratio }\end{array}$ & $\begin{array}{l}95 \% \text { confidence } \\
\text { interval }\end{array}$ & $\begin{array}{c}P \\
\text { value }\end{array}$ \\
\hline$C$ difficile infection status* & 5.449 & $(2.14-13.87)$ & .0004 \\
\hline Male sex & 0.535 & $(0.36-0.8)$ & .0023 \\
\hline Age & 1.036 & $(1.02-1.05)$ & $<.0001$ \\
\hline Creatinine, per mg/dL & 1.199 & $(1.09-1.31)$ & .0001 \\
\hline Diabetes (yes/no) & 1.569 & $(1.03-2.38)$ & .0350 \\
\hline Non- $C$ difficile infection status $\dagger$ & 4.063 & $(2.49-6.62)$ & $<.0001$ \\
\hline Heart failure (yes/no) & 2.011 & $(1.34-3.02)$ & .0007 \\
\hline
\end{tabular}

Recent results of an active surveillance study funded by the CDC's Emerging Infections Program showed that whereas the majority of CDI cases reported in the United States were related to health care exposure (ie, an inpatient or outpatient visit within 12 weeks before collection of a $C$ difficile-positive stool sample), only $24 \%$ of cases had an in-hospital onset. ${ }^{25}$ Thus, the data from the CTSN infection study provide a unique opportunity to examine the incidence of CDI in the cardiac surgery population and to explore risk factors associated with its occurrence, as well as the relationship between CDI and adverse outcomes.

As would be expected based on the CDC surveillance results, in the present study, nearly one-half of all CDIs (48\%) occurred after index hospital discharge, and 25\% of all CDIs occurred after 30 days. This may explain why the frequency of CDI in this study (50 patients; $0.97 \%$ ) was higher than the $0.21 \%$ to $0.75 \%$ reported from other national databases of cardiac surgery patients. ${ }^{24,48,49} \mathrm{CDI}$ was more common than expected during study planning and was in fact collected as an "other" serious infection. Thus, the diagnosis was not protocolized, but rather was determined according to standard clinical practice at each site.

Comorbidities have been frequently associated with the risk of CDI. ${ }^{1,2,8,9,11,17,24,31,33,34,50}$ Not surprisingly, we found that patients who developed CDI were more likely to suffer from renal failure preoperatively and more likely to have longer ICU LOS. Duration of ICU LOS and procedure were related; VAD and transplant recipients spent longer in the ICU than patients undergoing other procedures. Acute hyperglycemia was associated with an increased risk of CDI; however, whether hyperglycemia is indicative of a sicker, more vulnerable patient or if hyperglycemia in and of itself increases the risk of infection is unclear, particularly because diabetes was not associated with the risk of CDI and we did not observe a differential risk of hyperglycemia by diabetes. 
We did not find a significantly higher incidence of CDI associated with older age, diabetes, increased body mass index, or COPD; with urgent or emergent procedure status; in women; or in Caucasian patients as has been observed in other studies. ${ }^{9,12,13,17}$ In contrast, African Americans were the racial group that contracted CDI most frequently. Given that only 50 patients in this cohort contracted CDI and the cohort was predominantly male, our analysis may simply have been underpowered to detect a difference. It is also possible that varying diagnostic criteria by site may have obscured any risks associated with demographics. There was not a statistically significant difference in CDI incidence in patients who did not undergo a sternotomy compared to those who did, although it is worth noting that the incidence in both groups was low, so a difference would have to be fairly large to be detectable.

Moreover, other studies have identified additional risk factors for CDI, including malignancy, chemotherapy, intra-abdominal therapy, malnutrition, and previous CDI. ${ }^{33,34}$ Because the present study was designed to focus on management practices and the risk of infection, many of the variables identified in other studies as risk factors of CDI were not collected in this study.

Although patients with CDI were readmitted more often during the 65-day follow-up period, this appears to be indicative of the fact that hospital exposure and comorbidities increase the risk of CDI, given that readmissions tended to be for reasons other than $\mathrm{CDI}$; only 7 of the 31 readmissions in this group were due to CDI. In most cases, onset of CDI occurred during the index hospitalization or during a readmission hospitalization. Readmissions for CDI occurred in close proximity to hospital discharge, consistent with the CDC's surveillance study findings.

As was observed in other reports, ${ }^{1-4,6,8,9,12,17,21,32,50-52}$ CDI was associated with significantly increased mortality. This finding held after adjusting for age, sex, diabetes, $\mathrm{CHF}$, baseline creatinine, and time-varying non-C difficile infection (HR, 5.449; 95\% CI, 2.14-13.87; $P<.0004$ ). Mortality observed in patients with CDI in this cohort of cardiac surgery patients $(10.0 \%)$ was comparable to the death rates from health care-associated CDI in surgical and nonsurgical patients in the United States and Canada over the same time period $(6 \%-35 \%) .{ }^{53,54}$ Despite the fact that patients with CDI tended to generally be at higher risk for adverse outcomes, we did not observe an increase in any major adverse cardiac or cerebrovascular events other than death (ie, myocardial infarction, cerebrovascular accident, or transient ischemic attack) at any point during the 65-day follow-up. A single case of cerebrovascular accident occurring after onset of CDI was the sole nonfatal reported adverse event among the 50 patients ever diagnosed with CDI.
The risk of CDI increases substantially with prolonged antibiotic exposure, because suppression of the bowel flora allows $C$ difficile to flourish. ${ }^{55}$ This effect is thought to be particularly pronounced with secondgeneration cephalosporins. ${ }^{56}$ Antibiotic prophylaxis lasting $\leq 48$ hours was protective against CDI, but antibiotic prophylaxis lasting $\geq 3$ days was associated with higher risk of CDI regardless of type of antibiotic prophylaxis provided. We had anticipated that a previous postoperative infection would increase the risk of CDI, because the initial postoperative infection would presumably result in antibiotic treatment, yet only $28 \%$ of first CDI cases occurred after another infection (major or minor), and other (non- $C$ difficile) infection was not significantly associated with an increased risk of CDI.

Although the type of antibiotic was significant in univariable analyses, with second-generation cephalosporins associated with a decreased risk of CDI, the finding did not hold in a multivariable model, possibly because the type of antibiotic was correlated with the duration of antibiotic treatment. This also may be related to the limited size of the study (50 patients with CDI). A recent analysis of 154,200 cardiac surgery patients in the Premier database showed an association between antibiotic prophylaxis with cephalosporin and decreased risk of CDI (although it did not distinguish between first- and seond-generation cephalosporins). ${ }^{49}$ That study also confirmed an increased risk of CDI with antibiotic prophylaxis that extended past 48 hours.

\section{Limitations}

In this cohort of more than 5000 patients, the number of patients with CDI was low, limiting this study's statistical power. CDI was potentially underreported, because it was not included in the predefined list of major infections in the protocol; instead, it was captured as a serious "other" infection. Diagnostic criteria were not protocolized, and we do not know how each diagnosis was made (ie, nucleic acid amplification test vs other methods). However, the study was designed to capture all postoperative infections, all events were reviewed and adjudicated by an Event Adjudication Committee of infectious disease experts, and follow-up through the end of the study was $98 \%$ complete. Given the thoroughness of data capture and the fact that the reported incidence in this study was higher than that in other studies, ${ }^{1,2,4,13}$ we believe the likelihood of bias due to underreporting is low.

Medications other than prophylactic antibiotics were not captured in the database, which precluded an analysis of antibiotics administered for other infections occurring before CDI. It also precluded an analysis of medications, such as proton pump inhibitors, that have been previously identified as risk factors for $\mathrm{CDI} .{ }^{48,57}$ However, other infections, serious or not serious (before the onset of CDI 
in patients with CDI), were not associated with an increased risk of CDI.

Discharge disposition also was not captured in the database, precluding an analysis to determine if patients discharged to a rehabilitation or nursing facility were at increased risk of postdischarge CDI compared with patients who were discharged to home.

Finally, the data on excess LOS due to CDI should be interpreted with caution, because these data do not take into account other potentially informative covariates (eg, index surgical procedure). Because this study was designed to focus on management practices and infection, other complications and adverse events were not collected, and these variables may have affected LOS overall or in the ICU.

\section{CONCLUSIONS}

$\mathrm{CDI}$ is a common infection following cardiac surgery and is associated with significant increases in LOS and mortality. Despite intense efforts to reduce the incidence of health care-associated infections, opportunities to improve adherence to quality improvement measures remain, particularly glycemic control and optimal duration of antibiotic prophylaxis ( $\leq 48$ hours), to reduce the rates of CDI. High-risk patients, such as those with renal failure or those undergoing complex procedures, such as VAD placement or transplant, who will spend an extended length of time in the ICU, are particularly vulnerable to CDI and may warrant additional precautions to reduce the morbidity and mortality associated with CDI. Providers should continue to be vigilant about CDI after discharge, because onset frequently occurs more than 2 weeks after surgery.

\section{Conflict of Interest Statement}

Authors have nothing to disclose with regard to commercial support.

\section{References}

1. Zerey M, Paton BL, Lincourt AE, Gersin KS, Kercher KW, Heniford BT. The burden of Clostridium difficile in surgical patients in the United States. Surg Infect. 2007;8:557-66.

2. Keshavamurthy S, Koch CG, Fraser TG, Gordon SM, Houghtaling PL, Soltesz EG, et al. Clostridium difficile infection after cardiac surgery: prevalence, morbidity, mortality, and resource utilization. J Thorac Cardiovasc Surg. 2014; 148:3157-65.

3. Hall JF, Berger D. Outcome of colectomy for Clostridium difficile colitis: a plea for early surgical management. Am J Surg. 2008;196:384-8.

4. Lemaire A, Dombrovskiy V, Batsides G, Scholz P, Solina A, Brownstone N, et al. The effect of Clostridium difficile infection on cardiac surgery outcomes. Surg Infect. 2015;16:24-8.

5. Kelly CP, LaMont JT. Clostridium difficile-more difficult than ever. New Engl J Med. 2008;359:1932-40.

6. Sailhamer EA, Carson K, Chang Y, Zacharias N, Spaniolas K, Tabbara M, et al. Fulminant Clostridium difficile colitis: patterns of care and predictors of mortality. Arch Surg. 2009;144:433-40.

7. Kwon JH, Olsen MA, Dubberke ER. The morbidity, mortality, and costs associated with Clostridium difficile infection. Infect Dis Clin North Am. 2015; 29:123-34.
8. Crabtree T, Aitchison D, Meyers BF, Tymkew H, Smith JR, Guthrie TJ, et al. Clostridium difficile in cardiac surgery: risk factors and impact on postoperative outcome. Ann Thorac Surg. 2007;83:1396-402.

9. Greenstein AJ, Byrn JC, Zhang LP, Swedish KA, Jahn AE, Divino CM. Risk factors for the development of fulminant Clostridium difficile colitis. Surgery. 2008;143:623-9.

10. Dallal RM, Harbrecht BG, Boujoukas AJ, Sirio CA, Farkas LM, Lee KK, et al. Fulminant Clostridium difficile: an underappreciated and increasing cause of death and complications. Ann Surg. 2002;235:363-72.

11. Khanna S, Pardi DS. The growing incidence and severity of Clostridium difficile infection in inpatient and outpatient settings. Expert Rev Gastroenterol Hepatol. 2010;4:409-16.

12. Redelings MD, Sorvillo F, Mascola L. Increase in Clostridium difficilerelated mortality rates, United States, 1999-2004. Emerg Infect Dis. 2007; 13:1417-9.

13. Ricciardi R, Rothenberger DA, Madoff RD, Baxter NN. Increasing prevalence and severity of Clostridium difficile colitis in hospitalized patients in the United States. Arch Surg. 2007;142:624-31.

14. Salazar M, Baskin L, Garey KW, DuPont HL. Clostridium difficile-related death rates in Texas, 1999-2005. J Infect. 2009;59:303-7.

15. Warny M, Pepin J, Fang A, Killgore G, Thompson A, Brazier J, et al Toxin production by an emerging strain of Clostridium difficile associated with outbreaks of severe disease in North America and Europe. Lancet. 2005;366: 1079-84.

16. Zilberberg MD, Shorr AF, Kollef MH. Increase in adult Clostridium difficile-related hospitalizations and case-fatality rate, United States, 2000-2005. Emerg Infect Dis. 2008;14:929-31.

17. Mocanu V, Buth KJ, Johnston LB, Davis I, Hirsch GM, Legare JF. The importance of continued quality improvement efforts in monitoring hospital-acquired infection rates: a cardiac surgery experience. Ann Thorac Surg. 2015;99:2061-9.

18. Morris AM, Jobe BA, Stoney M, Sheppard BC, Deveney CW, Deveney KE Clostridium difficile colitis: an increasingly aggressive iatrogenic disease? Arch Surg. 2002;137:1096-100.

19. Stewart DB, Hollenbeak CS. Clostridium difficile colitis: factors associated with outcome and assessment of mortality at a national level. J Gastrointest Surg. 2011;15:1548-55.

20. McDonald LC, Killgore GE, Thompson A, Owens RC Jr, Kazakova SV Sambol SP, et al. An epidemic, toxin gene-variant strain of Clostridium difficile. New Engl J Med. 2005;353:2433-41.

21. Elixhauser A, Jhung M. Clostridium difficile-Associated Disease in US Hospitals, 1993-2005. Healthcare Cost and Utilization Project Statistical Brief 50. Rockville, Md: Agency for Healthcare Research and Quality; 2006.

22. Inkster T. Antibiotic prophylaxis for cardiac surgery: a shift away from traditional cephalosporins? J Cardiothorac Vasc Anesth. 2009;23:933-5.

23. Wysowski DK. Increase in deaths related to enterocolitis due to Clostridium difficile in the United States, 1999-2002. Public Health Rep. 2006;121:361-2.

24. Flagg A, Koch CG, Schiltz N, Chandran Pillai A, Gordon SM, Pettersson GB, et al. Analysis of Clostridium difficile infections after cardiac surgery: epidemiologic and economic implications from national data. J Thorac Cardiovasc Surg. 2014;148:2404-9.

25. Lessa FC, Mu Y, Bamberg WM, Beldavs ZG, Dumyati GK, Dunn JR, et al Burden of Clostridium difficile infection in the United States. N Engl J Med. 2015;372:825-34.

26. Aguayo C, Flores R, Lévesque S, Araya P, Ulloa S, Lagos J, et al. Rapid spread of Clostridium difficile NAP1/027/ST1 in Chile confirms the emergence of the epidemic strain in Latin America. Epidemiol Infect. 2015;143:3069-73.

27. Ngamskulrungroj P, Sanmee S, Pusathit P, Piewngam P, Elliott B, Riley TV, et al Molecular epidemiology of Clostridium difficile infection in a large teaching hospital in Thailand. PloS One. 2015;10:e0127026.

28. Nanwa N, Kendzerska T, Krahn M, Kwong JC, Daneman N, Witteman W, et al The economic impact of Clostridium difficile infection: a systematic review. Am J Gastroenterol. 2015;110:511-9.

29. Dubberke ER, Olsen MA. Burden of Clostridium difficile on the healthcare system. Clin Infect Dis. 2012;55(Suppl 2):S88-92.

30. Desai K, Gupta SB, Dubberke ER, Prabhu VS, Browne C, Mast TC Epidemiological and economic burden of Clostridium difficile in the United States: estimates from a modeling approach. BMC Infect Dis. 2016;16:303.

31. Bishara J, Peled N, Pitlik S, Samra Z. Mortality of patients with antibiotic-associated diarrhoea: the impact of. Clostridium difficile. J Hosp Infect. 2008;68:308-14. 
32. Musa SA, Moran C, Thomson SJ, et al. Clostridium difficile-associated disease acquired in the cardiothoracic intensive care unit. J Cardiothorac Vasc Anesth. 2011;25:263-7.

33. Khanafer N, Vanhems P, Barbut F, Luxemburger C. Factors associated with Clostridium difficile infection: a nested case-control study in a three year prospective cohort. Anaerobe. 2017:44:117-23.

34. Huang H, Wu S, Chen R, Xu S, Fang H, Weintraub A, et al. Risk factors of Clostridium difficile infections among patients in a university hospital in Shanghai, China. Anaerobe. 2014;30:65-9.

35. Fowler VG Jr, O'Brien SM, Muhlbaier LH, Corey GR, Ferguson TB, Peterson ED. Clinical predictors of major infections after cardiac surgery. Circulation. 2005;112(9 Suppl):I358-65.

36. Abboud CS, Wey SB, Baltar VT. Risk factors for mediastinitis after cardiac surgery. Ann Thorac Surg. 2004;77:676-83.

37. Gelijns AC, Moskowitz AJ, Acker MA, et al. Management practices and major infections after cardiac surgery. J Am Coll Cardiol. 2014;64:372-81.

38. Horan TC, Andrus M, Dudeck MA. CDC/NHSN surveillance definition of health care-associated infection and criteria for specific types of infections in the acute care setting. Am J Infect Control. 2008;36:309-32.

39. Ailawadi G, Chang HL, O'Gara PT, O'Sullivan K, Woo YJ, DeRose JJ Jr, et al. Pneumonia after cardiac surgery: experience of the National Institutes of Health/ Canadian Institutes of Health Research Cardiothoracic Surgical Trials Network. J Thorac Cardiovasc Surg. 2017;153:1384-91.

40. Perrault LP, Kirkwood KA, Chang HL, Mullen JC, Gulack BC, Argenziano M, et al. A prospective multi-institutional cohort study of mediastinal infections after cardiac surgery. Ann Thorac Surg. 2017 [Epub ahead of print].

41. Fine JPGR. A proportional hazards model for the subdistribution of a competing risk. J Am Stat Assoc. 1999;94:496-509.

42. Zhou B, Fine J, Laird G. Goodness-of-fit test for proportional subdistribution hazards model. Stat Med. 2013;32:3804-11.

43. Furnary AP, Wu Y. Clinical effects of hyperglycemia in the cardiac surgery population: the Portland Diabetic Project. Endocr Prac. 2006;12(Suppl 3):22-6.

44. Székely A, Levin J, Miao Y, Tudor IC, Vuylsteke A, Ofner P, et al. Impact of hyperglycemia on perioperative mortality after coronary artery bypass graft surgery. J Thorac Cardiovasc Surg. 2011;142:430-7.

45. Cardona S, Pasquel FJ, Fayfman M, Peng L, Jacobs S, Vellanki P, et al. Hospitalization costs and clinical outcomes in CABG patients treated with intensive insulin therapy. J Diabetes Complications. 2017;31:742-7.

46. Greco G, Ferket BS, D’Alessandro DA, Shi W, Horvath KA, Rosen A, et al. Diabetes and the association of postoperative hyperglycemia with clinical and economic outcomes in cardiac surgery. Diabetes Care. 2016;39:408-17.
47. Allignol A, Schumacher M, Beyersmann J. Empirical transition matrix of multi-state models: the etm package. J Stat Softw. 2011;38:1-15.

48. Bateman BT, Rassen JA, Schneeweiss S, Bykov K, Franklin JM, Gagne JJ, et al. Adjuvant vancomycin for antibiotic prophylaxis and risk of Clostridium difficile infection after coronary artery bypass graft surgery. $J$ Thorac Cardiovasc Surg. 2013;146:472-8.

49. Poeran J, Mazumdar M, Rasul R, Meyer J, Sacks HS, Koll BS, et al. Antibiotic prophylaxis and risk of Clostridium difficile infection after coronary artery bypass graft surgery. J Thorac Cardiovasc Surg. 2016;151:589-97.

50. Karanika S, Paudel S, Zervou FN, Grigoras C, Zacharioudakis IM, Mylonakis E. Prevalence and clinical outcomes of Clostridium difficile infection in the intensive care unit: a systematic review and meta-analysis. Open Forum Infect Dis. 2016;3:ofv186.

51. Mazzeffi M, Gammie J, Taylor B, Cardillo S, Haldane-Lutterodt N, Amoroso A, et al. Healthcare-associated infections in cardiac surgery patients with prolonged intensive care unit stay. Ann Thorac Surg. 2017;103:1165-70.

52. Bruminhent J, Cawcutt KA, Thongprayoon C, Petterson TM, Kremers WK, Razonable RR. Epidemiology, risk factors, and outcome of Clostridium difficile infection in heart and heart-lung transplant recipients. Clin Transplant. 2017;31 [Epub ahead of print].

53. Hota SS, Achonu C, Crowcroft NS, Harvey BJ, Lauwers A, Gardam MA. Determining mortality rates attributable to Clostridium difficile infection. Emerg Infect Dis. 2012;18:305-7.

54. Centers for Disease Control and Prevention. Nearly half a million Americans suffered from Clostridium difficile infections in a single year. CDC Newsroom Release. February 25, 2015. Available at: https://www.cdc.gov/media/releases/ 2015/p0225-clostridium-difficile.html. Accessed June 25, 2015.

55. Gorbach SL. Antibiotics and Clostridium difficile. N Engl J Med. 1999;341: 1690-1.

56. Nelson DE, Auerbach SB, Baltch AL, Desjardin E, Beck-Sague C, Rheal C, et al. Epidemic Clostridium difficile-associated diarrhea: role of second- and third-generation cephalosporins. Infect Control Hosp Epidemiol. 1994;15: 88-94.

57. Aseeri M, Schroeder T, Kramer J, Zackula R. Gastric acid suppression by proton pump inhibitors as a risk factor for Clostridium difficile-associated diarrhea in hospitalized patients. Am J Gastroenterol. 2008;103:2308-13.

Key Words: Clostridium difficile infection, cardiac surgery, antibiotic prophylaxis 


\section{APPENDIX E1. CTSN INVESTIGATORS}

The following members of the Cardiothoracic Surgical Trials Network (CTSN) were involved in this study:

National Heart, Lung and Blood Institute: Marissa A. Miller, Wendy C. Taddei-Peters, Dennis Buxton, Ron Caulder, Nancy L. Geller, David Gordon, Neal O. Jeffries, Albert Lee

National Institute of Neurological Disorders and Stroke: Claudia S. Moy

Canadian Institutes of Health Research: Ilana Kogan Gombos, Jennifer Ralph

Network Chairs: Christiana Care Health System, Timothy J. Gardner, (Chair); Brigham and Women's Hospital, Patrick T. O'Gara, (Co-Chair)

Data Coordinating Center: International Center for Health Outcomes and Innovation Research at Icahn School of Medicine at Mount Sinai, Annetine C. Gelijns, Michael K. Parides, Deborah D. Ascheim, Alan J. Moskowitz, Ellen Moquete, Eric A. Rose, Melissa Chase, Yingchun Chen, Rosemarie Gagliardi, Lopa Gupta, Edlira Kumbarce, Ron Levitan, Karen O’Sullivan, Milerva Santos, Alan Weinberg, Paula Williams, Carrie Wood, Xia Ye

Core Clinical Site Investigators: Cleveland Clinic Foundation, Eugene H. Blackstone (PI), A. Marc Gillinov, Pamela Lackner, Leoma Berroteran, Diana Dolney, Suzanne Fleming, Roberta Palumbo, Christine Whitman, Kathy Sankovic, Denise Kosty Sweeney; NHLBI Clinical Research Scholars: Gregory Pattakos, Pamela A. Clarke; Columbia University, Michael Argenziano (PI), Mathew Williams, Lyn Goldsmith, Craig R. Smith, Yoshifumi Naka, Allan Stewart, Allan Schwartz; Daniel Bell, Danielle Van Patten; Duke University, Peter K. Smith (PI), Stacey Welsh, John H. Alexander, Carmelo A. Milano, Donald D. Glower, Joseph P. Mathew, J. Kevin Harrison; NHLBI Clinical Research Scholars: Mark F. Berry, Cyrus J. Parsa, Betty C. Tong, Judson B. Williams; East Carolina Heart
Institute, T. Bruce Ferguson (PI), Alan P. Kypson, Evelio Rodriguez, Malissa Harris, Brenda Akers, Allison O’Neal; Emory University, John D. Puskas (PI), Vinod H. Thourani, Robert Guyton, Jefferson Baer, Kim Baio, Alexis A. Neill; Montefiore-Einstein Heart Center, New York, NY, Robert E. Michler (PI), David A. D’Alessandro, Joseph J. DeRose, Jr, Daniel J. Goldstein, Ricardo Bello, William Jakobleff, Mario Garcia, Cynthia Taub, Daniel Spevak, Roger Swayze; Montreal Heart Institute, Louis P. Perrault (PI), Arsène-Joseph Basmadjian, Denis Bouchard, Michel Carrier, Raymond Cartier, Michel Pellerin, Jean François Tanguay, Ismael El-Hamamsy, André Denault, Jonathan Lacharité, Sophie Robichaud; NIH Heart Center at Suburban Hospital, Keith A. Horvath (PI), Philip C. Corcoran, Michael P. Siegenthaler, Mandy Murphy, Margaret Iraola, Ann Greenberg; University of Pennsylvania, Michael A. Acker (PI), Y. Joseph Woo, Mary Lou Mayer; University of Virginia, Irving L. Kron (PI), Gorav Ailawadi, Karen Johnston, John M. Dent, John Kern, Jessica Keim Sandra Burks, Kim Gahring

Protocol Review Committee: David A. Bull (Chair); Patrice Desvigne-Nickens, Executive Secretary; Dennis O. Dixon, Mark Haigney, Richard Holubkov, Alice Jacobs, Frank Miller, John M. Murkin, John Spertus, Andrew S. Wechsler

Data and Safety Monitoring Board: Frank Sellke (Chair); Cheryl L. McDonald, Executive Secretary; Robert Byington, Neal Dickert, Dennis O. Dixon, John S. Ikonomidis, David O. Williams, Clyde W. Yancy

Medical Monitors: James C. Fang, Wayne Richenbacher Overall Event Adjudication Committee: Vivek Rao (Chair); Karen L. Furie, Rachel Miller, Sean Pinney, William C. Roberts

Infection Event Adjudication Committee: Rachel Miller (Chair); Shirish Huprikar, Marilyn Levi 